\title{
The Validity of the Pharmacy Projects and Research: A New Initiative in the Kingdom of Saudi Arabia
}

\author{
Yousef Ahmed Alomi*, iD BSC. Pharm, \\ MSc. Clin Pharm, BCPS, BCNSP, DiBA, CDE, \\ Critical Care Clinical Pharmacists, TPN \\ Clinical Pharmacist, Freelancer Business \\ Planner, Content Editor and Data Analyst, \\ Riyadh, Saudi Arabia. \\ Basmah Sulimain AlHamdan, BSC. \\ Pharm, MSc, Senior Quality Specialist, King \\ Fahad Medical City, Riyadh, Saudi Arabia.
}

\section{Correspondence:}

Dr. Yousef Ahmed Alomi, BSc. Pharm, MSc. Clin Pharm, BCPS, BCNSP, DiBA, CDE, Critical care clinical pharmacists, TPN Clinical Pharmacist, Freelancer Business Planner, Content Editor and Data Analyst, P.O.BOX 100, Riyadh 11392, Riyadh, Saudi Arabia.

Phone no: +966504417712

E-mail: yalomi@gmail.com
Received: 10-09-2019;

Accepted: 26-11-2019.

Copyright: (c) the author(s),publisher and licensee Pharmacology, Toxicology and Biomedical Reports. This is an open-access article distributed under the terms of the Creative Commons Attribution NonCommercial License, which permits unrestricted non-commercial use, distribution, and reproduction in any medium, provided the original work is properly cited.

This is an open access article distributed under the terms of the Creative Commons Attribution-NonCommercial-ShareAlike 4.0 License

Access this article online

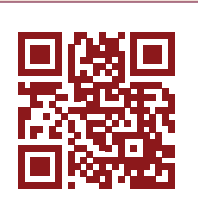

www.ptbreports.org

DOI:

10.5530/PTB.2020.6.7

\begin{abstract}
Objectives: To declare the validity tools used in the pharmacy practice project or research in the Kingdom of Saudi Arabia. Methods: It is a new initiative project of the validity of pharmacy projects and research. The projects drove the international validity guidelines, the global business model and pharmacy project guidelines project management institution guidelines of a new project. The initial project is written through project management professionals and contained of several parts, including the initial phase, the planning phase, the execution phase, the monitoring and controlling phase. Results: The validity of the pharmacy projects and research services that defined vision, mission and goals. The services had multiple benefits, including clinical and economical on the healthcare system, as described in the review. The continuation of the services assured by risk management elements description. Moreover, the monitoring and controlling of the projects as illustrated. The transition to operation project though the closing project stage shown in the analysis. Conclusion: The validity of pharmacy projects and research is a new initiative project in pharmacy quality management and pharmacy research tools. Various methods of validation procedure services can be underway in the pharmacy practice to validate the appropriate and collection of the pharmacy data and it is highly suggested in the Kingdom of Saudi Arabia.

Key words: Validity, Pharmacy, Projects, Research, Services, Initiative, Saudi Arabia.
\end{abstract}

\section{INTRODUCTION}

The pharmacist performed several activities in the pharmacy practice and had a clinical benefit and economic outcomes. However, the validity of all pharmacy performance dealings the same outcomes without deviation. It needs tools of validation to implement at each group of performance with an emphasis on the survey that's been scattered to the pharmacy customer, including patients or healthcare professionals. Several publications had done for pharmacy surgery's or questioners and seldom finding locally, or Gulf and Middle East countries deliberated the validity, while brief was more common. ${ }^{1-7}$ The aim of the current project is to declare the validity project in the pharmacy practice as a new initiatives project in the Kingdom of Saudi Arabia.

\section{Method of the Project}

It is a new initiative project drove by the pharmacy research program. The task force team of authors as pharmacy researcher and expert research pharmacists. The committee utilized and drove the validity in the pharmacy research and new projects with an emphasis on surveys from the textbook and international literature reliability written by utilizing the global business model, pharmacy project guidelines project management institution guidelines of a new project..$^{8-11}$ The validity of pharmacy research or surveys depends on biostatistical and forthright analysis tests for reliability. The project is written through project management professionals and contained of several parts, including the initial phase, the planning phase, the execution phase, the monitoring and controlling phase.
Initiative Phase

\section{Assessment Needs}

The validation tools was used most commonly in pharmacy or medical research. However, validity processes is not widely used in pharmacy practice projects. It highly difficulties to assure the accuracy of the results with appropriate survey or construction of the project. The tool needed to organize the construction validation of the project or pharmacy survey. Most of the pharmacy services at different locations in the Kingdom of Saudi Arabia have not applied those tools within pharmacy practice projects.

\section{Market Analysis}

Multiple universities in the Kingdom of Saudi Arabia with importance on the phaermacy colleges implemented the validation tools in the pharmacy researches. Besides, some pharmaceutical manufacturers applied those tools during their pharmacy projects during or after the implementation phase. However, the majority of the pharmacy leaders at different locations of pharmacy services not implemented those tools with quality or non-quality management services.

\section{SWOT Analysis}

There are predictable methods of tools called the SWOT Analysis, which means the strengths, weaknesses and opportunities elements. The strength points of the project are to assure the methods to reach goals not changed, prevent mistakes or deviation in the goal measurements. On the other hand, the weak points are limited need expert trained pharmacists to perform and need. Also, the opportunity points are the qual- 
ity management pharmacy program application and elements of the accreditation procedures besides, the threat points are if the administration banner which is not obtainable and if the pharmacy strategic plan which does not happen.

\section{Planning Phase}

\section{Scope of the Project}

The project shelters some of the pharmacy researches and projects, especially with a survey dispersed to the patients or pharmacists. Besides, some total quality management in the pharmacy practice and training research project for undergraduate and post-graduate candidates with all levels of pharmacy residency programs.

\section{Vision, Missions, Goals}

The validity defined as "the degree to which the researcher has measured what he has set out to measure".12

The vision of the project is the best and high validity for all fitting pharmacy research and projects, while the message is to provide validity tools and skills for all pharmacists and pharmacy technicians for their research and new projects. The aim of the project is to implement the validity processes for all applicable pharmacy research, to implement the validity for all new pharmacy projects, to review all pharmacy surveys and questioners had been used, to validate all essential pharmacy practice data and evade any unnecessary wastage pharmacy data.

\section{Project Description}

The survey should be revised by team research revised self-sufficiently. Each member revised all survey content questions based on the updated literature and experience. Any defilements had been sent to all team research for further discussion and agreements. The survey had been corrected and agreement from the research team. One of the team members transferred all the surveys to Arabic language and double-checked by all team members again for content and accurate translation.

\section{Face Content Validity}

The principle authors intended the survey and team research revised self-reliantly. Each member revised all survey content questions based on the updated literature and experience. Any violations had been sent to all team research for further discussion and agreements. The survey had been corrected and agreement from the research team. The team members transferred all the surveys to specified language and double-checked by all team members again for content and accurate translation. ${ }^{12,13}$

\section{Construct Validity}

\section{Exploratory Factorial Analysis}

The method waws used for the construct validity of the survey. The factor was used univariate description and Kaiser-Myer-Olin measure of sampling adequacy and Bartlett's test sphericity. The extraction used principal components analysis, the Eigenvalues greater than 1 with the maximum iteration of convergence 25 and display through un-rotated faction solution and scree plot. The rotation used Varimax. ${ }^{14,15}$

\section{Confirmatory Factor Analysis}

The test was done through Statistical Package of Social Sciences-Analysis of Moment Structures (SPSS-Amos) and Jeffrey's Amazing Statistics Program (JASP) software programs with factor variances, R-Sequated, fit measurements, factor loading, without emulation, error calculated with CI 95\% and robust method, it was with the auto estimator and without standardization, it was with pathway analysis. ${ }^{14,15}$

\section{Collinearity}

The test was done through JASP with linear regression for collinearity diagnostics including Eigenvalue and condition index, the coefficient used with CI 95\% tolerance and variance inflation factor, the model fit through ANOVA and autocorrelation with Durbin-Watson. ${ }^{16}$

\section{Plan Cost Management}

The current new project, the management team, should identify the cost budget, which includes the cost of training and educational courses and the cost of the management team meeting. The budget should be monitored throughout the project.

\section{Executing Phase}

\section{Management Team}

The project should establish by task force contained of expert clinical pharmacists and pharmacy supervisor and total pharmacy quality. The team should implement the following project. The clinical and economical in the healthcare system should be strong-minded with regular updating of the validity of the pharmacy projects and research. The team should request from the pharmacy supervisor or clinical pharmacists to adaptive system to implement the validity of the pharmacy projects and research before staring.

\section{Education and Training}

The current new project demands education for validation tools for clinical pharmacists and pharmacy supervisors and any clinical pharmacist or pharmacist supervisor started-besides, education and training for healthcare professionals, including project validation and related issues. The team management member should have an orientation about the project and any new pharmacy or healthcare staff join the institutions.

\section{Monitoring and Controlling Phase}

\section{Project Total Quality Management}

The total quality management with the new project validation of pharmacy research or project is one of the critical tools to monitor the employment and the project impact assessment. There are several total quality tools used with the current project and the balance scored cards was one of them. The tools display four-parts that including the customer, finance, internal process, education and innovation. An example of internal processes was the assessment of pharmacy or healthcare services of validation of pharmacy researches or projects. In the education and innovation types, the measures of clinical outcome of validation of pharmacy researches or projects which could reproduce the education and capability of clinical pharmacists and pharmacy supervisor, the financial type the measurement of the economic impact of validation of pharmacy researches or projects. The customer types might measure the pharmacy and healthcare providers, including pharmacy staff, validation of pharmacy researches or project satisfaction in the Kingdom of Saudi Arabia.

\section{Risk Management}

The risk management had multiple types that are including budget risks, scope risks, schedule risks, personal risks, technical risks and quality risks. The project could be exposed to risks such as personnel, budget, technical and quality. The project may be had personal risks for an instant; there is not a trained pharmacy staff supervisor or not expert clinical pharmacy. Another risk with the budget types, for example, nontrained pharmacist supervisor or clinical pharmacists.

Scope risk was another example of the current project that's might be prolonged the meaning of the project or fight with other concepts. Besides, the budget risks might depiction to the projects, for instance, if there is not enough budget for education and training or update resources. On 
the other hand, the technical risk may be exposed that there is a computerized system during validity of the pharmacy projects and research. The new project might be exposed to quality risks related non-available validity of the pharmacy projects and research measures or shortage of total quality management pharmacist.

\section{Closing of the Project}

The validity of the pharmacy projects and research at various healthcare hospitals and primary healthcare centers with different governmental and private sectors is highly suggested to prevent errors related issues in the pharmacy practice with high-quality data and evade additional mistakes and unnecessary cost on healthcare services in the Kingdom of Saudi Arabia. The project should continue at pharmacy research units and clinical pharmacy development at each pharmacy department with the involvement of related committees. The education and training of the validity of the pharmacy projects and research should be showed regularly. Update and validity of the pharmacy projects and research are required in the future. The annual celebration of all pharmacist supervisor and clinical pharmacists with encourage them is highly recommended in Saudi Arabia.

\section{ACKNOWLEDGEMENT}

None.

\section{CONFLICT OF INTEREST}

The authors declare no conflict of interest.

\section{ABBREVIATIONS}

KSA: Kingdom of Saudi Arabia; SWOT: Strengths, Weaknesses, Opportunities and Threats; ANOVA: Analysis of Variance, SPSS: Statistical Package of Social Sciences; JASP: Jeffrey's Amazing Statistics Program; SPSS-Amos: Statistical Package of Social Sciences-Analysis of Moment Structures.

\section{REFERENCES}

1. Awaisu A, Bakdach D, Elajez RH, et al. Hospital pharmacists' self-evaluation of their competence and confidence in conducting pharmacy practice research. Saudi Pharm J. 2015;23(3):257-65

2. Carol A, Martha BIK. Pharmacists' views on involvement in pharmacy practice research: Strategies for facilitating participation. Pharm Pract. 2007;5(2):59-66.

3. Abubakar U, Sulaiman SAS, Usman MN, et al. Nigerian pharmacists' self-perceived competence and confidence to plan and conduct pharmacy practice research. Pharm Pract. 2018;16(1):115.

4. Kritikos VS, Carter S, Moles RJ, et al. Undergraduate pharmacy students' perceptions of research in general and attitudes towards pharmacy practice research. Int J Pharm Pract. 2013;21(3):192-201.

5. Fakeye TO, Adisa R, Olukotun RT, et al. Hospital and community pharmacists' perception of the scope, barriers and challenges of pharmacy practice-based research in Nigeria. Pharmacy Practice. 2017;15(1):881.

6. Bahmaid RA, Karim M, Al-Ghamdi N, et al. Impact of research educational intervention on knowledge, attitudes, perceptions and pharmacy practices towards evidence-based medicine among junior pharmacists. Cureus. 2018;10(6):1-18.

7. Ashri N, Al-Amro H, Hamadah L, et al. Dental and medical practitioners' awareness and attitude toward evidence-based practice in Riyadh, Saudi Arabia: A comparative study. Saudi J Dent Res. 2014;5(2):109-16.

8. McDonough R. Writing a Business Plan for a New Pharmacy Service. The Dynamics of Pharmaceutical Care: Enriching Patients' Health. 2010;23.

9. Harris IM, Baker E, Berry TM, et al. Developing a business-practice model for pharmacy services in ambulatory settings. Pharmacotherapy. 2008;28(2):7e34 e.

10. Sachdev G. Sustainable business models: Systematic approach toward successful ambulatory care pharmacy practice. Am J Heal Pharm. 2014;71(16):1366-74.

11. PMBOK Guide. A Guide to the Project Management Body of Knowledge. Sixth Edition. Project Management Institute, Inc. 2017.

12. Kumar R. Research Methodology a step-by-step guide for beginners. $3^{\text {rd }}$ edition. SAGE Publications Ltd. 2011.

13. Jain $S$, Dubey $S$, Jain S. Designing and validation of a questionnaire. Int Dent Med J Adv Res. 2016;2(1):1-3

14. Mackenzie SB, Podsakoff PM, Podsakoff NP, et al. Construct measurement and validation procedures in mis and behavioral research: Integrating new and existing techniques. MIS Q. 2011;35(2):293-334.

15. Hervás A, Guàrdia OJ, Peró CM, et al. A structural equation model for the analysis of factors associated with the choice of engineering degrees in a technical university. Abstr Appl Anal. 2013.

16. Dormann CF, Elith J, Bacher $\mathrm{S}$, et al. Collinearity: A review of methods to deal with it and a simulation study evaluating their performance. Ecography. 2013;36(1):27-46. 